\section{The effects of eye position and expectation on sound localization}

\author{
THEODORE C. WEERTS* and WILLARD R. THURLOW \\ Unjversity of Wisconsin, Madison, Wisconsin 53706
}

Ss who are exposed to a sound coming from straight ahead, but who turn their eyes 20 deg to the side toward a visible speaker during the exposure period and expect to hear the sound coming from the visible source, show a shift in localization of the sound up to a maximum of about $9 \mathrm{deg}$. Ss who only turn their eyes $20 \mathrm{deg}$ to the side during the exposure period show a smaller but significant shift in sound localization, while Ss who do not turn their eyes, but are led to expect that the sound will appear to come from a visible loudspeaker 20 deg to the side, show no significant shift. Comparison of test results before and after the exposure period, with eyes directed straight ahead and no visible speaker present, shows the presence of a localization aftereffect for those experimental groups that showed a significant localization shift during the exposure period. Sounds are localized a few degrees to the side of their physical location in the same direction as the shift in localization during the exposure period. Further experiments show that part, but not all, of the shift in localization during the exposure period can be understood in terms of a shift in perceived head direction. The localization aftereffects are shown not to be due to change in physical or perceived eye or head position.

Several experiments in recent years have shown that exposure to "discordant" auditory and visual cues for a period of time will lead to an "aftereffect" in which localization of sounds is systematically displaced. For instance, after wearing a pseudophone that displaces a sound $15 \mathrm{deg}$ to the right of a visible source, Ss hear a sound presented straight in front of them (from a concealed source) as displaced a few degrees to the left (Kalil \& Freedman, 1967). Freedman, Wilson, and Rekosh (1967) have found similar effects after discordant auditory and kinesthetic cues are presented to the $S$ for a period of time.

It is possible that these aftereffects could arise simply from asymmetrical auditory stimulation (see Flügel, 1921). Control groups are needed in which $\mathrm{Ss}$ arc simply exposed to asymmetrical auditory stimulation.

We ran a preliminary experiment (with the same equipment as that used in experiments described later in this paper) in which (1) an experimental group was exposed for $40 \mathrm{~min}$ to a sound coming from a concealed source $20 \mathrm{deg}$ to the left of the $S$. (For another group the concealed source was $20 \mathrm{deg}$ to the right.) There was a visible loudspeaker straight in front of

*This report is hased on research carried out by T.C. Weers for the degrec of Master of Science at the University of Wixconsin. under the direction of W. R. Thurlow. The research was supported by a trant $(6 ; 35329)$ from the National Science loundation Io W. R. Thurlou We are also indebted to the (iraduate Research Committee. Iniversity of Wixconsin. for pecia! funds for computer time the $S$. The $S$ was led by the instructions to expect that he should eventually hear the sound coming from the visible speaker. Ss showed an "aftereffect" shift of about $7 \mathrm{deg}$ when tested after the "exposurc" period with six concealed sources from $17 \mathrm{deg}$ left to $17 \mathrm{deg}$ right. (2) A control group followed the same procedure except that $S$ s were blindfolded and received no instructions leading them to believe that the perceived location of the sound source would shift toward straight ahead of them. These Ss also showed an aftereffect of about $7 \mathrm{deg}$.

Thus, it appears that substantial aftereffects can be produced that are explainable by adaptation within the auditory system. IIt should be added that the aftereffects reported by Held (1955) in an earlier experiment did appear to be a function also of the characteristics of the motor response utilized by the $S$ during the exposure period.l

Are there any aftereffects following exposure to discordant auditory and visual cues when symmetrical audilory stimulation is used? One of the aims of the experiments reported in the present paper was to answer this question. Another aim of the present experiments was to explore the shifts in sound localization that occur in an exposure period when the $S$ is under the impression that the sound (from a conccaled source) is coming from a source (such as a loudspeaker) that is visible to him. ("Ventriloquism" effects are in this same gencral problem area.) Witkin. Warner, and leventhal (1952) and Jackson (1953) have measured the effect of a visible potential source on the localization of sound. There is no question that sizable shifts in sound localization can be produced. Further analytical experimentation is desirable, however, to determine the roles of such factors as eye position of the $S$ and his expectancy that the visible source is the actual source of the sound.

\section{Apparatus}

\section{SET 1 EXPERIMENTS}

The $S$ sat in an experimental room, as indicated in Fig. 1, facing 0 deg. Six loudspeakers (Realistic, 2.5-in. djam) were located in front of $S$ at $17 \mathrm{deg}$ left, $10 \mathrm{deg}$ left, 4 deg left, 4 deg right, $10 \mathrm{deg}$ right, and $17 \mathrm{deg}$ right of straight ahead. The loudspeakers were each 36 in. from $S$ and were suspended 36 in. above the floor (about shoulder height for a seated S). They were concealed by a cloth curtain. A 3-in. cardboard strip, visible to the $S$, was placed 3 in. below the speakers and was marked off in degrees. The walls and cciling were lined with fiberglass wedges to absorb sound. The experimental room was acoustically isolated from outside sounds.

The stinuli were clicks, at a rate of $9.6 / \mathrm{sec}$, controlled by a Grason-Stadler interval timer (Model 471) so that they sounded for $5 \mathrm{sec}$ and were then followed by an off period of $8 \mathrm{sec}$. The clicks were produced by passing $.5-\mathrm{msec}$ pulses from a pulse generator (Grason-Siadler, Model 876A) through two $5,000-\mathrm{Hz}$, band-pass filters (UTC, Model 4c), then through an attenuator and transformer to one of the test speakers. These speakers could be switched on individually by the $\mathrm{E}$.

\section{Screening Session}

Ss, who were undergraduate students, were selected on the basis of their threshold sensitivity and for their ability to localize clicks coming from the concealed loudspeakers. A threshold test at $5,000 \mathrm{~Hz}$ was performed in another room. Ss were selected who: (1) had a threshold no more than $10 \mathrm{~dB}$ below average and (2) had no more than $10 \mathrm{~dB}$ threshold difference between their ears.

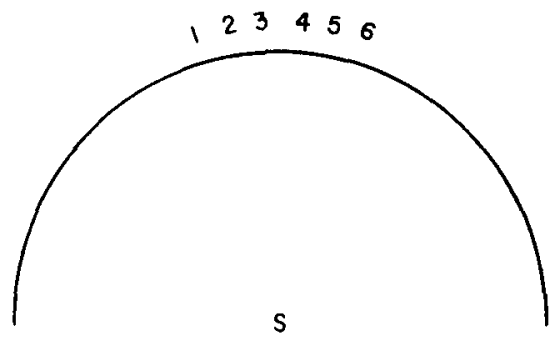

Fig. 1. Diagram of position of $S$ in experimental room. Semicircle indicates position of cloth screen and scale. Numbers indicate position of loudspeakers. 
Table 1

Conditions of Experiment 1

\begin{tabular}{llll} 
Groups & $\begin{array}{c}\text { Eye Position During } \\
\text { Exposure Period }\end{array}$ & $\begin{array}{c}\text { Expectation of the } \\
\text { Click Source During } \\
\text { Exposure Period }\end{array}$ & $\begin{array}{c}\text { Eye Position } \\
\text { During Pretest } \\
\text { and Post test }\end{array}$ \\
\hline EX 1 & $20 \mathrm{deg}$ to the side & $20 \mathrm{deg}$ to the side & free to move \\
EX 2 & $20 \mathrm{deg}$ to the side & $20 \mathrm{deg}$ to the side & fixed at 0 deg \\
CX 1 & straight ahead & $20 \mathrm{deg}$ to the side & free to move \\
EC 1 & 20 deg to the side & none & free to move \\
CC 1 & straight ahead & none & free to move \\
\hline
\end{tabular}

The localization test was performed in the room diagrammed in Fig. 1. The clicks were set at $30 \mathrm{~dB}$ above S's threshold. The order of presentation of speakers was random, except for the restriction that all of the six speakers were presented before repeating any one of them. Each speaker was presented five times. When the clicks went off, $S$ pointed directly to the perceived location of the clicks along the semicircular dial with a flashlight pointer, holding his arm straight and fully extended. If the average of the last four readings for any of the six speakers represented an error greater than $5 \mathrm{deg}$, the $S$ was rejected.

\section{Pretest and Posttest}

Each $S$ first performed a localization pretest similar to the screening localization test, followed by a 40-min experimental condition and a repetition of the localization test (posttest). Table 1 presents a summary of the most important features of the experimental conditions.

For four groups, EX1, CX1, EC1, and $\mathrm{CC} 1$, the test procedure was like the screening test, except that $\mathbf{S}$ had his head strapped to a head brace attached to the chair. For a fifth group, EX2, Ss were also required to keep their eyes fixed straight ahead. A fixation point was provided, and E observed S's eyes through a mirror.

\section{Exposure Period}

Groups EXI and EX2. An 8-in. loudspeaker was placed on a stand several inches in front of the cloth screen at the same height as the concealed speakers behind the screen. This visible speaker was always placed at an angle of $20 \mathrm{deg}$ from the direction $S$ was facing. Of the 20 Ss in each group, 10 had the visible speaker placed $20 \mathrm{deg}$ to the left and $10 \mathrm{had}$ it placed 20 deg to the right.

$S$ was instructed to turn his eyes to the side and to look at the center of the visible speaker at all times. $S$ was told that the clicks would be emitted simultaneously from several of the concealed speakers and would perceptually add up to appear to be coming from the visible speaker. $S$ was told that the clicks might not appear to be coming from the visible speaker at first, but would as he adapted to the situation. $S$ was instructed to point (with the flashlight pointer in his right hand) to where he heard the clicks as soon as the clicks went off each time. ( $S$ was told that on trials when he heard the clicks coming directly from the visible speaker, he did not have to point.) S's arm was well within his field of vision while pointing. His head was strapped to the head brace, as it was in testing.

The $40 \mathrm{~min}$ of training were divided in to 10 series of 18 trials. At the end of each series, $S$ was rotated in his chair so that he faced one of the concealed speakers, and the visible speaker was moved so as to be $20 \mathrm{deg}$ to $\mathrm{S}$ 's side. For the group of Ss who had the visible speaker to their left, the directions the $S$ faced in successive series were: $4 \mathrm{deg} R, 10 \mathrm{deg} \mathrm{R}, 4 \mathrm{deg}$ left, $17 \operatorname{deg} \mathrm{R}, 10 \operatorname{deg} \mathrm{L}, 4 \operatorname{deg} \mathrm{L}, 10 \operatorname{deg} \mathrm{R}$, $17 \mathrm{deg} \mathrm{R}, 10 \mathrm{deg} \mathrm{L}$, and $4 \mathrm{deg} \mathrm{R}$. The directions for the group of Ss who had the visible speaker to their right were: $4 \mathrm{deg} \mathbf{L}$, $10 \operatorname{deg} \mathrm{L}, 4 \operatorname{deg} \mathrm{R}, 17 \mathrm{deg} \mathrm{L}, 10 \mathrm{deg} \mathrm{R}$, $4 \operatorname{deg} R, 10 \operatorname{deg} L, 17 \operatorname{deg} L, 10 \operatorname{deg} R$, and 4 deg $L$.

Mounted on top of the visible speaker was a $6-V$ incandescent red light. E turned on the light 30 times during the exposure period (three times in each of 10 series) when S's attention appeared to be waning. $S$ was given a pushbutton which he was instructed to press to turn off the light.

After the 10th series, the visible speaker was removed, $S$ was turned to face $0 \mathrm{deg}$, and the post test was begun.

Groups $C X I$ and $E C l$. The experimental procedures for these groups were identical to those of EXI and EX2 with one exception each. For Group CX1 the red light was placed on a separate stand directly in front of $S$ just below the level of the concealed speakers, and $S$ was told to fix his eyes on it. The visible loudspeaker was placed $20 \mathrm{deg}$ to the side, as before, and $S$ was instructed to expect to hear the clicks coming from it. For Group EC. 1 the visible loudspeaker was removed and the red light was used in its place. $S$ was required to turn his eyes to the side and focus on the red light but was not instructed concerning the expected location of the click source.

Group $C C 1$. The experimental procedure for Group $\mathrm{CCl}$ differed from Groups EX1 and EX2 in two ways. S neither tooked to the side nor expected to hear the clicks from the side while localizing them. The red light was placed directly in front of $S$, and he fixed his eyes on it.

\section{Results}

Localization shifts during the exposure period. As a measure of the effects produced, the difference was tabulated between the S's localization response and the true location of the concealed loudspeaker (straight ahead of S). A positive difference was taken as a shift toward the direction of the visible loudspeaker (or toward the direction in which the eyes were turned, or toward the direction in which E's suggestion indicated the sound should be heard).

Average difference scores are plotted for the 10 series of each of the five groups of $20 \mathrm{Ss}$ in Fig. 2. It appears from Fig. 2 that turning the eyes toward the visible speaker, together with the expectation that the sound would be heard coming from the visible speaker (Groups EX1 and EX2) produced the largest effects. Simply turning the eyes toward the visible speaker (Group EC1) appeared to produce some effects but of smaller magnitude. The expectation that the sound would come from the visible speaker (Group $\mathrm{CX}$ 1) did not alone seem to produce any variation different from that of the control group (Group CC1).

The results of an analysis of variance showed that all of the following were significant at $p<.01$ : (1) groups,

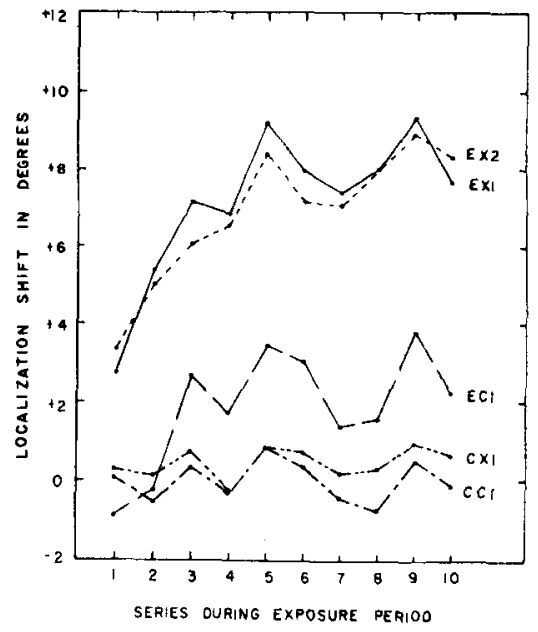

Fig. 2. Localization shift, in degrees, during the exposure period for experimental and control groups, Set 1 experiments. A positive shift is one toward the direction of the visible loudspeaker and/or toward the direction to which the eyes are turned. See Table 1 for explanation of symbols. 


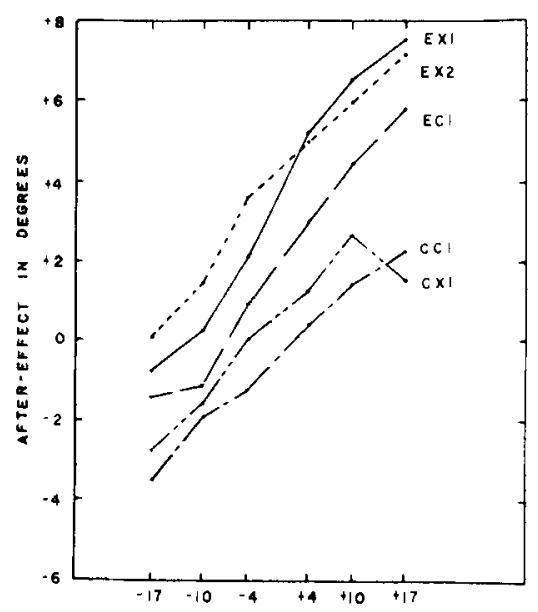

TEST SPEAKER POSITION

Fig. 3. Localization aftereffects, in degrees, as a function of test loudspeaker position, Set 1 experiments. A positive shift is one which is in the same direction as the position of the visible loudspeaker during the exposure period and/or the direction to which the eyes were turned during the exposure period. Test speaker position is given in degrees, with reference to straight ahead $(0 \mathrm{deg})$. A positive value indicates a loudspeaker in the same direction as the position of the visible loudspeaker during the exposure period and/or the direction to which the eyes were turned during the exposure period.

$F(4,90)=22.16$, (2) series $\mathrm{F}(9,810)=36.31$, (3) Groups by Series, $F(36,810)=4.81$, and (4) Direction of Training by Series, $F(9,810)=3.35$.

Subsequent Newman-Keuls tests produced the following results for the main groups effects: EX1 EX2 EC1 CX1 CC1. (Groups above the same underline are not significantly different. Groups not above the same underline are different at $\mathrm{p}<.05$ )

A trend test on the series effects indicated that the five experimental curves in Fig. 2 were of different shapes. (Details of these trend tests and of other tests described in the present paper are given in Weerts, 1969.) Trend tests performed un all combinations of groups, two at a time. showed that the curves of Groups EX1, $\mathrm{EX} 2$, and EC1 were of the same shape and differed trom the curves of Groups $\mathrm{CX1}$ and $\mathrm{CC} 1$

The various statistical tests reinforce our tentative conclusions derived from looking at the results plotted in Fig. 2: EX1 and EX2 are producing the largest effects, EC 1 is producing an intermediate effect, and $\mathrm{CXI}$ is producing no more effect than the $\mathrm{CCl}$ control group. It is of interest that the largest average effect produced is of the order of $9 \mathrm{deg}$. The "influence" effect is not the total $20 \mathrm{deg}$. Pick, Warren, and Hay (1969) have reported partial shifts also. In addition, the effect is not an immediate or all-or-none effect. There is an increase in effect over time.

Aftereffects. Sound localization shifts were determined from pretest to posttest. The average of the last four readings from the pretest were subtracted from the average of the last four readings from the posttest for each of the six speaker positions. This shift in localization is plotted in Fig. 3. A positive sign was given to a shift whenever it was in the direction of the visible speaker (or direction of - turning the eyes, or direction of expectation during the exposure period). Positive values for the speaker locations on the baseline represent speakers in the direction of the visible speaker (in degrees from straight ahead), while negative values represent speakers in the direction away from the visible speaker.

Examination of the average results in Fig. 3 indicates in general the same rank ordering for magnitude of aftereffects as for shifts during application of the experimental treatments. At the same time, it is obvious that the average amount of aftereffect shift is less than the shift during the exposure period and that there is a systematic difference in aftereffect as a function of speaker position.

Analysis of variance revealed that the following effects were significant at $p<.01$ : (1) groups, $F(4,90)=15.10$, (2) speaker position, $F(5,450)=109.34$, and (3) Group by Speaker Position, $F(20,450)=1.61$. Subsequent Newman-Keuls tests produced the following results for the groups effect: EX1 EX2 ECl CX1 CC1. (Groups above the same underline are not significantly different. Groups not above the same underline are different at $p<.05$.)

The results of a trend test on speaker position effects showed that the linear and cubic components of the main effect of speaker position were significant beyond the .01 level. There were no significant interaction effects. Thus, the curves of Fig. 3 are assumed to be of the same shape and parallel. In making the trend analyses on aftereffects, it was assumed that, so far as the $S$ was concerned, the test speakers were equally spaced. This assumption appears reasonable when one considers the degree of uncertainty of localization of these sources.

Since the control condition CC 1 shows the same slope as the experimental groups, the slope effect is not produced by the experimental treatments during the exposure period. The slope may reflect a type of neural fatigue effect. Several Es have reported that sounds are shifted in localization away from a point that has been fatigued by another sound (see, for instance, Krauskopf, 1954; Taylor, 1962).

Average aftereffects produced by the experimental treatments can be seen, then, in Fig. 3 to be reflected in curves that are shifted upward from the control curve. The largest effects were produced in groups that combined turned eyes and expectation (EX1 and EX2). Aftereffects for Group EX2 were as large as those for Group EX1, even though Ss in Group EX2 held their eyes fixed on a fixation point during pretest and posttest. This latter result indicates that one cannot argue that the aftereffects are somehow related to a changed extent of eye movement during the posttest caused by the experimental treatment during the exposure period or that the aftereffects are due to a bias in eye position.

Even though rank order of magnitude of average localization shift produced by an experimental treatment tended to be the same as the rank order for magnitude of aftereffect produced by that treatment, magnitude of individual localization shifts and aftereffects were by no means highly related to each other. Correlations between the average aftereffect shift and the average shift during the exposure period were +.43 $(\mathrm{p}<.06)$ and $+.62(\mathrm{p}<.01)$ for Groups EX1 and EX2, respectively. The correlations for the other three groups did not approach significance.

\section{SET 2 EXPERIMENTS}

Experiments in Set 2 were performed to explore the role of several variables that might have contributed to effects that had been observed in Set 1 experiments.

(1) It might be argued that the aftereffects observed in Set 1 experiments were due to slight turning of the head in the posttest period, produced by the experimental treatment. Therefore, additional precautions were used during pretest and posttest to keep the head of the $\mathrm{S}$ (as well as his eyes) fixed in direction.

(2) Even if physical position of the eyes and head is controlled, it might be argued that perceived eye and head direction is changed in the posttest due to the exposure conditions. Therefore, measurements of perceived eye and head direction were made both during pretest and posttest and during the exposure period.

(3) It is conceivable that part of the effects observed might be due to a "conditioning" of new significance to auditory localization cues with respect to 
Table 2

Experimental Conditions of Experiment 2

\begin{tabular}{|c|c|c|c|c|c|}
\hline \multirow[b]{2}{*}{ Groups } & \multicolumn{3}{|c|}{ Exposure Period* } & \multicolumn{2}{|c|}{ Pretest and Posttest } \\
\hline & $\begin{array}{c}\text { Eye Position } \\
\text { Relative } \\
\text { to Head }\end{array}$ & $\begin{array}{c}\text { Expectation } \\
\text { of Click } \\
\text { Source }\end{array}$ & $\begin{array}{c}\text { Head Position } \\
\text { Relative } \\
\text { to Body }\end{array}$ & $\begin{array}{c}\text { Head } \\
\text { and Eyes } \\
\text { Fixed at } \\
0 \text { Deg }\end{array}$ & $\begin{array}{l}\text { Felt Head } \\
\text { and Eye } \\
\text { Position } \\
\text { Measurements }\end{array}$ \\
\hline EXH 1 & 20 right & 20 right & 20 left & yes & not taken \\
\hline EXH 2 & 20 right & 20 right & 20 left & $\begin{array}{c}\text { no } \\
\text { (blindfolded) }\end{array}$ & not taken \\
\hline EXH 3 & 20 right & 20 right & 20 left & yes & taken \\
\hline EXC 3 & 20 right & 20 right & straight ahead & yes & taken \\
\hline $\operatorname{ccc} 3$ & straight ahead & none & straight ahead & yes & taken \\
\hline
\end{tabular}

* Felt head position measurements were taken for all groups during the exposure period.

body direction. Therefore, body direction was shifted so that if such a conditioning was taking place, the aftereffect would be expected to occur in the opposite direction to that found previously.

(4) Finally, there is a possibility that some distortion of the visual framework, caused by the experimental treatments, was contributing to the aftereffects observed. Therefore, one experimental group was blindfolded during the pretest and posttest.

\section{Procedure}

The procedures were very similar to those described under Set 1 experiments. Therefore, only changes from the procedures previously described will be given. Table 2 presents an outline of the various treatments for the five groups of Ss. There were $10 \mathrm{Ss}$ in each group.

Pretest and posttest. All groups except EXH2 (in which Ss were blindfolded during testing) were tested with head and eyes fixed. $S$ was seated in the chair facing 0 deg with his head strapped to a head brace. A beam of light was reflected from a small mirror located on the bridge of S's nose onto a red $X$ marked on a stand located at 0 deg. If $S$ moved his head, the spot of light would move. $S$ was instructed to focus on the red $X$ and to keep the spot of light on it. E monitored the S's eyes by means of a mirror.

For Groups $\mathrm{EXH} 3, \mathrm{EXC} 3$, and $\mathrm{CCC} 3$, perceived eye direction and perceived head direction were measured. (1) Just before starting the pretest and following the posttest, $S$ was instructed to close his eyes, keeping them facing straight in his head, and to point with the flashlight pointer in the direction he felt his eyes to be facing. Following this $\mathrm{S}$ was instructed to open his eyes, fix them so they felt straight in his head, and then point to where he was looking. (2) During the pretest and posttest, $S$ indicated his felt head direction in the following two ways: $S$ indicated his felt head direction with his eyes closed before Trials 1, 13, and 25 and with his eyes open and fixed on the red $X$ after Trials 6,18 , and 30 .
Exposure period. Measurements of perceived head direction were taken for all five groups of Ss (see Table 2). At the end of each 5-sec series of clicks, S was asked for an indication of perceived head direction. For alternate series of clicks, S (1) closed his eyes and pointed to the direction he felt his head was facing, and (2) fixed his eyes on the center of the visible speaker and pointed to where he feit his head was facing. Ss of Group CCC3, who had no visible speaker, fixated a red light in front of them for this measurement.

Group CCC3 was run in essentially the same manner as Group CC1 of Set 1 (and Group EXC3 was essentially the same as Group EX2 of Set 1), except for the measurements of perceived eye and head direction.

Groups EXH1, EXH2, and EXH3 were different from Groups EXC3 and $\mathrm{CCC} 3$ in that Ss of the former groups were seated with their bodies facing the visible loudspeaker, at $20 \mathrm{deg}$ right, rather than facing $0 \mathrm{deg}$. Their head direction was still $0 \mathrm{deg}$, just as in Groups EXC3 and CCC3 and in the groups of Set 1 experiments. In Groups EXH1, EXH2, EXH3, and EXC3, S's eyes were turned $20 \mathrm{deg}$ to the right (toward the visible speaker) and Ss were instructed to expect to hear the clicks as coming from the visible speaker. Instructions to create this expectancy were the same as in Set 1 experiments.

\section{Results}

Localization shifts during exposure period. The localization readings from each of the 10 series of trials were averaged and the difference was taken between this average and the location of the concealed speaker. This difference score is plotted in Fig. 4 across the 10 series of trials for all groups. A positive difference represents a localization to the right of the concealed loudspeaker.

The results of an analysis of variance showed the following significant effects: (1) groups, $F(4,45)=9.32, p<.01$, (2) series, $F(9,405)=10.61, p<.01$, and (3) Groups by Series, $F(36,405)=1.53$,

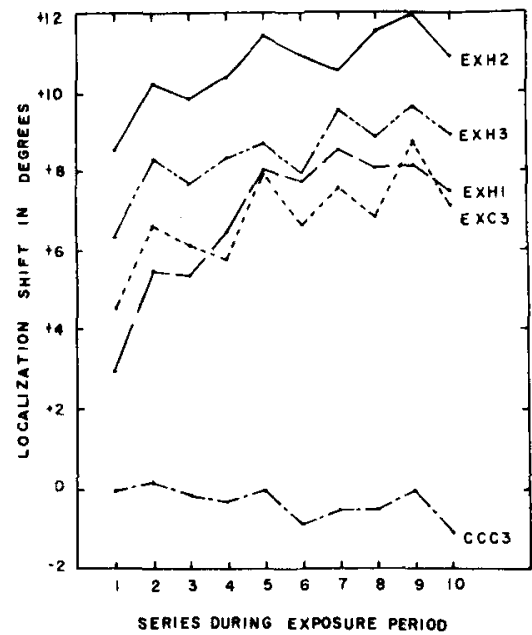

Fig. 4. Localization shift, in degrees, during the exposure period for experimental and control groups, Set 2 experiments. A positive shift is defined as in Fig. 2. See Table 2 for explanation of symbols.

$p<.05$. Subsequent Newman-Keuls tests (.05 level) on the groups effect showed that the shift in localization was greater for all experimental groups than for the control group but that the experimental groups did not differ significantly. This means that turning the body $20 \mathrm{deg}$ to the right to face the visible speaker does not change the results from those obtained when the body is facing straight ahead.

Results of measurements of perceived head direction during the exposure period are shown in Fig. 5. The eyes open and closed measurements are combined because statistical analysis showed no significant differences. The analysis of variance showed that the main effect of series

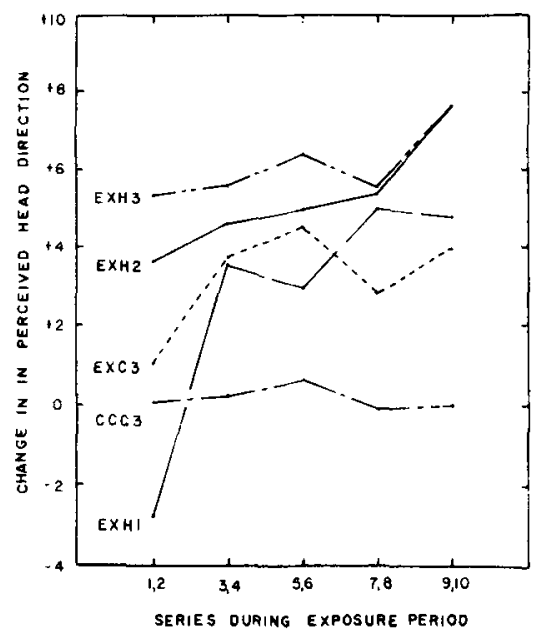

Fig. 5. Change in perceived head direction, in degrees, during the exposure period, Set 2 experiments. A positive change is defined as in Fig. 2. 


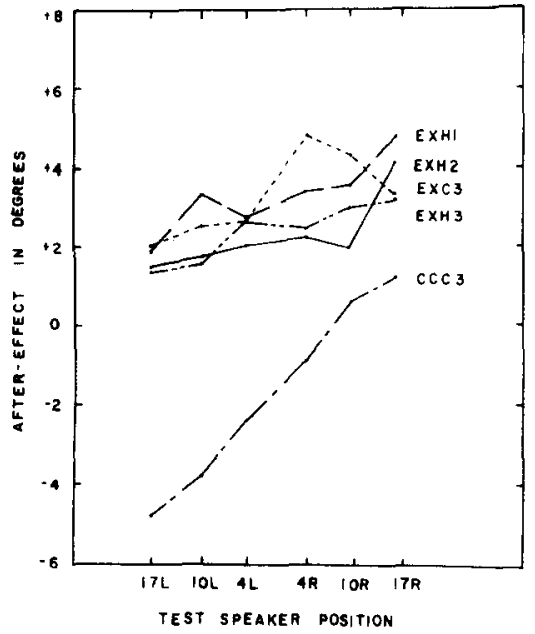

Fig. 6. Localization aftereffects, in degrees, as a function of test loudspeaker position, Set 2 experiments. A positive shift is defined as in Fig. 3.

$[F(4,180)=7.51, \quad p<.01]$ and the interaction effects of Groups by Series $[F(16,180)=1.85, p<.05]$ were the only significant effects. While the analysis of variance did not show a significant groups effect, a linear comparisons test between Control Group CCC3 and the four experimental groups was significant at the .05 level.

Aftereffects. For each $\mathrm{S}$ the average of the last four readings from the pretest were subtracted from the average of the last four readings from the posttest for each of the six test speakers. This measure of sound localization shift is presented for each of the five groups in Fig. 6. An analysis of variance showed groups $[F(4,45)=5.62$, $\mathrm{p}<.01]$ and test speaker position $[F(5,225)=9.02, p<.01]$ were the only significant effects. Subsequent Newman-Keuls (.05 level) tests showed that the aftereffect was greater for ail experimental groups than for the control group but that the experimental groups did not differ significantly.

Trend tests showed that only the linear componen: of the main effect of series was significant. The Groups by Test Speaker Position interaction was not significant; the curves of Fig. 6, therefore, are not significantly different in slope. In comparing aftereffects for the experimental groups in Fig. 6 with those in Fig. 3 of the first set of experiments, one has the strong impression that, even though the average aftereffects are similar, the slopes have changed. We had felt that the slopes in Set 1 experiments were in a sense superimposed on the average aftereffects and represented different mechanisms. This impression is strengthened by the Set 2 experimental results. A further series of experiments is being performed to investigate factors which influence the slope.

Analysis of variance did not indicate that the exposure period had any statistically significant effect (.05 level) in changing the S's localization of his eye direction or head direction between pretest and posttest.

\section{Localization Shifts Produced During Exposure to Experimental Treatments}

The Set 1 series of experiments showed that there was a significant effect of turning of the eyes on sound localization. Some earlier experiments had reported such effects (Goldstein \& Rosenthal-Viet, 1926), though Ryan and Schehr (1941) were not able to replicate these findings. The effects of eye turning in our Set 1 experiments were small, however. The Set 1 series of experiments showed that the largest effect on localization was produced by combining the turning of eyes with the expectation that the sound would be perceived as coming from the loudspeaker toward which the eyes were directed. This is the set of cues which typically functions when one turns one's eyes toward an actual source.

Part of the significant shifts could be caused by a shift in the direction in which the head is perceived as facing (probably related to turning of the eyes). Yet the shift in sound localization in Set 2 experiments was greater than the shift in perceived direction of the head. Thus, shift in perceived head position cannot account for all of the shift in localization observed.

It is of interest that expectation alone did not produce a significant effect. The significant effects observed are thus not due to a simple form of "suggestion."

There are other variables which our Set 2 experiments show do not have an effect on the shifts in localization. Turning the body with respect to the head did not alter the general results observed. (It had been thought that turning the body might cause more shift in perceived head direction and, thus, shift in sound localization.) (hange in felt arm position could not be regarded as a cause of the shifted localization: Direction of straight ahead obtained by having the $S$ point with eyes closed was not different from direction of straight ahead obtained by having the $S$ point with eyes open. If there had been a shift in felt arm position, the results would have been expected to be different.

\section{Localization Aftereffects}

Consistent localization aftereffects were found, even though auditory stimulation was kept equal at the two ears, and extra precautions were taken to rule out turning of eyes and head during pretest and posttest. Furthermore, these aftereffects are not due to shifts in perceived eye position or head position.

There are other explanations of these aftereffects which can be ruled out by our experiments:

(1) The aftereffect is not due to a shift in felt arm position because, as already mentioned, there was no evidence for change in felt arm position.

(2) The aftereffect is apparently not due to development of some distortion in the visual field, because essentially the same results are obtained with the $\$ s$ blindfolded during pretest and posttest.

(3) Development of a slight bias in pointing in response to suggestion that the sound is coming from one side can be ruled out, because no aftereffect occurs in the simple "suggestion" condition.

(4) The aftereffect cannot be due to "conditioning" of a response with respect to body "straight-ahead" direction. When body direction was changed so that the perceived sound was to the left of body straight ahead during the exposure period, aftereffect was still to the right.

\section{REFERENCES}

F ÜGEL, J. C. On local fatigue in the auditory system. British Journal of Psychology, 1921, 11, 105-134.

I'REEDMAN, S. J., WILSON, L.. \& REKOSH, J. $H$. Compensation for auditory re-arrangement in hand-ear coordination. Perceptual \& Motor Skills, 1967, 24, 1207-1210.

GOLDSTEIN, K., \& ROSENTHAL-VIET, $O$. Über akustische Lokalisation und deren Beeinflussbarkheit durch andere Sinnesreize. Psychologische Forschung, 1926, 8, 318-335.

HELD, R. Shifts in binaural localization after prolonged exposures to atypical combinations of stimuli. American Journal of Psychology, $1955,68,526-548$.

JACKSON. C. V. Visual factors in auditory localization. Quarterly Journal of lixperimental Psychology, 1953, 5, 52-65.

KALIL., R., \& FREEDMAN, S. J. Compensation for auditory re-arrangement in the absence of observer movement. Perceptual \& Motor Skills, $1967,24.475-478$.

KRAUSKOPI, J. ligural aftereffects in auditory space. American Jeurnal of Psychology, 1954. 67, 278-287.

PICK, H. L., WARREN, D. H., \& HAY, J. C. Sensory conflict in judgments of spatial direction. Perception \& Psychophysics, 1969, 6, 203-205.

RYAN, T. A., \& SCHEHR, I. The influence of cye movement and position on auditory localization. American Journal of Psychology, $1941,54,243-252$.

TAYLOR, M. M. The distance paradox of the figural aftereffect in auditory localization. Canadian Journal of Psychology, 1962, 16, 278-282.

WEIRTS. T. W. The effects of eye position and expectation on sound localization. Unpubliched Master's thesis, University of Wisconsin, 1969.

WITKIN, H. A.. WAPNER, S., \& LEVENTHAL, $T$. Sound localization with conflicting visual and auditory cues. Journal of lixperimental Psychology, 1952, 43, 58-67.

(Accepted for publication April 14. 1970.) 